INTERNATIONAL DESIGN CONFERENCE - DESIGN 2018

https://doi.org/10.21278/idc.2018.0368

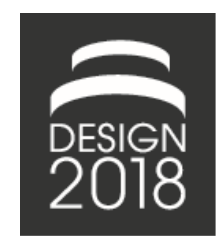

\title{
CHALLENGES IN THE DEFINITION AND PRIORITISATION OF REQUIREMENTS: A CASE STUDY
}

\author{
Y.-W. Song, M. Windheim and B. Bender
}

\begin{abstract}
A big challenge in the definition and prioritisation of requirements for a new product is to find compromises when conflicts arise. What is the best compromise depends on the objectives of the specific development context. After developing an explanation based on literary theory, the here presented case study describes an exemplary development context to better understand the correlating influencing factors in this decision process in real development projects. Based on the findings, three hypotheses are developed and requirements for a methodical support are derived.
\end{abstract}

Keywords: requirements management, requirements engineering, case study, integrated product development

\section{Introduction}

Products are associated with many objectives from different stakeholders. In the early phase of product planning, these objectives are often still vague expectations that have to be sharpened by formulating testable requirements to clarify and specify the development task and to verify the outcome afterwards (Pahl et al., 2007; Ehrlenspiel, 2009; Feldhusen and Grote, 2013). Considering this important role in the development process, incorrect, changing or incomplete requirements lead inevitably to time and cost consuming iterations. The dilemma in product development is that the necessary information and knowledge to define the right requirements is most uncertain in this early stage. Even in development projects that start on the basis of previous product generations, which is the most common case in industry (Albers et al., 2015), requirements definition is still a very challenging task. Launching a new product generation to the market means to provide new or at least improved features or characteristics, otherwise customers are not very attracted to buy them. The new or improved features usually cause high development efforts. Therefore, defining the requirements for a new product means finding the right compromise between the achievable customer benefit and the affordable development effort. This decision depends on the priorities in the specific development context (e.g. available budget/resources, pricing strategy, market position). At this point the paper contributes to a deeper understanding of possible causes and circumstances by presenting a case study that describes this problem within an industrial development context.

The goal of this paper is to develop a comprehensive exploration of this requirements definition and prioritisation problem. Initially a more extensive problem description based on literary theory will be given (Section 2) and then an empirical case study will be described to better understand this problem with influences from the boundary conditions in a real product development project (Section 3). This will answer the research question: How does this problem manifest in the corporate context of the power tool company Hilti? Based on these findings, requirements for a prospective methodical support are derived in Section 4. That ensures to develop a practicable and needs-oriented support in the further steps, as for that 
reason methods are usually not developed on an abstract basis, but on a concrete context or problem (Bogner et al., 2014). So, this paper is situated in the phase of 'Research Clarification' and 'Descriptive Study I' according to the Design Research Methodology by Blessing and Chakrabarti (2009).

\section{Problem description}

The increasing competitive pressure forces companies more than ever into an innovation campaign. Innovation is always the result of a renewal process that either extends existing knowledge or applies available knowledge to a new context (Ericson and Kastensson, 2011). However, the development of innovative products is inherently fraught with risks. On the one hand, risks result from the fact, that at the beginning of the innovation project the expected customer benefit caused by the innovation to be developed can merely be anticipated. Although methodological support by means of prototypes, mockups or cognitive walkthrough can be used, reliable statements, particularly regarding the actual perceived benefit for the customer, can only be made after finalisation of the product and market launch. On the other hand, risks are inherent in the realization of the product idea, since both the technical and economic feasibility of the product are not yet fully verified in the early stages of product development. Due to the complexity of the desired product, its development is rather characterised as a problemsolving-process with many iterations where new information is gained and implemented (Pahl et al., 2007; Ehrlenspiel, 2009; Feldhusen and Grote, 2013). Costs and time requirements are also difficult to calculate on beforehand since new development activities, methods and tools might be required (Stockstrom and Herstatt, 2008). So, these risks result in the early phase from uncertainties which are to be understood as a consequence of insufficient experience and missing knowledge/information (McManus and Hastings, 2006). The dilemma (Figure 1, left side) is, that despite high uncertainties in this early phase, central decisions about the design must be made as early as possible since the costs of change increase with ongoing development progress (Ehrlenspiel, 2009).

These considerations show a direct correlation between the level of risk and the degree of novelty of any innovative product. This correlation also shows that the risk increases the more ambitious the objective of the development project is. But on the other hand, it is also obvious that a causal correlation between the degree of novelty of an innovation and its economic potential can be assumed, because a higher degree of novelty also promises a correspondingly higher increase of the customer benefit.
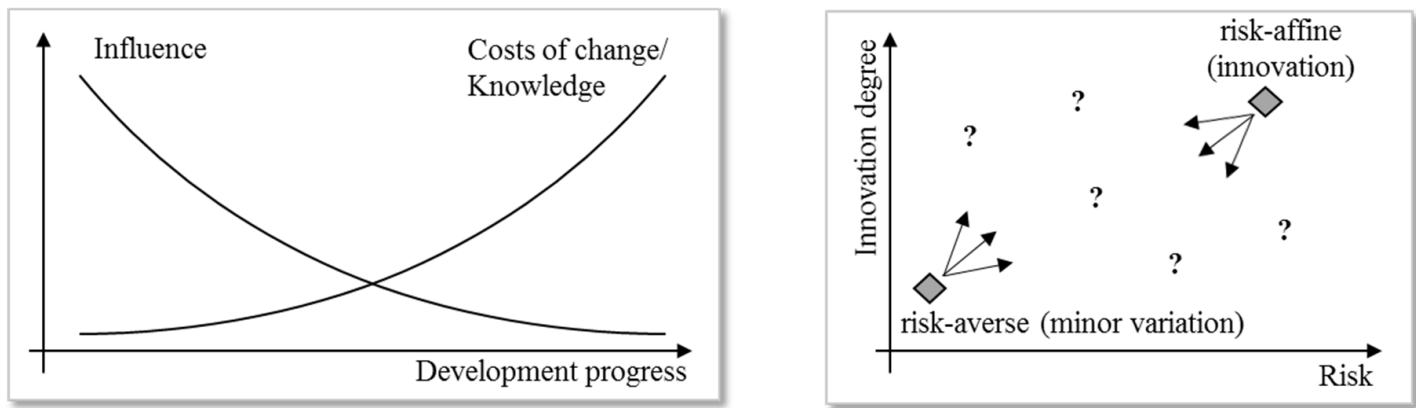

Figure 1. The paradox of product development (Ehrlenspiel, 2009) (left side); compromise between modest and ambitious requirements (right side)

These conflicting correlations can be observed in two opposing strategies in industrial practice. With the goal to consciously avoid risks, companies either reuse proven product structures and solution elements (Wyatt et al., 2009; Jarratt et al., 2011; Albers et al., 2015). Especially complex products are generally created through incremental modifications of solutions which matured over several product generations (Eckert et al., 2010). This is described by Albers et al. (2015) as product generation development. But as a result, the degree of innovation and thus the economic potential are relatively low (Vajna, 2014). On the opposite, less risk-averse companies often set their targets too high, so in case of occurring risks their innovation projects remain unprofitable and can end with a total loss of investment in the worst case (Cooper, 2002). The assumption of the approach presented here is therefore, that for each design context (Gericke et al., 2013) as described by specific objectives and boundary conditions, a suitable compromise must be found between innovation leap on the one hand and 
acceptable risk on the other hand (Figure 1, right side). In tendency, both values increase with the innovation leap, but also are associated with increasing risks.

This compromise must be identified in the early planning phase, when fundamental requirements are defined, and which therefore plays a central role for the entire product development process. Requirements and in particular requirement-changes compared to previous product generations determine the (improved) customer benefit and thus the economic potential of the innovation as well as the risk of the development effort. This emphasizes the importance of an active and conscious definition of the requirements in early phases (Oerding, 2009; Muschik, 2011).

That process requires different perspectives and can be supported by established requirements engineering approaches i.a. for the elicitation, analysis and specification of requirements to align the product with the customer needs from the beginning. Elicitation methods (e.g. brainstorming, interviews/questionnaires, market analysis, benchmarking, checklists, integration of prototypes, etc.) can be used to compile an initial requirements list (Pohl, 2010; Incose, 2011, Zehnter et al., 2012). The structuring and prioritisation of these requirements, beyond a classification into demands and wishes, can be supported by analysis methods (e.g. Kano model, house of quality, conjoint analysis, etc.), showing the correlations between the defined requirements and the resulting customer satisfaction (Kano et al., 1984; Akao, 2004; Pahl et al., 2007; Ehrlenspiel, 2009; Feldhusen and Grote, 2013). There are also approaches that determine the necessary changes of the product architecture (technical realisation) or the necessary costs and time effort (e.g. Aguirre-Ollinger and Stahovich, 2004; Chua and Hossain, 2012). Also approaches to evaluate the associated risks of these development efforts exist in terms of quality (e.g. Clarkson et al., 2004; Koh et al., 2012), time and costs (e.g. Browning and Eppinger, 2002; Roser et al., 2003). The aim of the following case study is to explore, how these different perspectives are integrated in the early phase of product planning to define requirements in an industrial development project and how this company handles the challenges in practice.

\section{Case study}

The case study presented in this section was conducted at the power tool company Hilti. Case studies are subsumed among qualitative empirical research. Its purpose is to capture the contextual variability of a phenomenon, which shall help to deeply understand this phenomenon and to generate hypotheses for its explanation (Borchardt and Göthlich, 2007; Yin, 2014). Whether these hypotheses are generalisable or representative can be tested with quantitative empirical research methods (e.g. surveys), since a more objective validity can be accomplished due to the larger sample (Bamberg and Bauer, 1998; Yin, 2014). Eisenhardt (1989) argues that the important strengths of building theories from case studies are their testability and empirical validity, which arises from the linkage with empirical evidence. In combination with observations from literature, case study research is particularly useful in early stages of research in a new area, as it is applied here.

\subsection{Research methodology}

This case study focuses on the challenges in the definition and prioritisation of requirements of new power tools at the Hilti corporation. In-depth interviews with two experts about their retrospective and current experiences were conducted to gain a profound understanding of this research subject in a reallife context (explorative/informational function) and hence to substantiate preliminary considerations and formulate explaining hypotheses (theory-generating function).

\section{Survey method: Expert interviews}

The strength of expert interviews is not to investigate their technical knowledge, for which analysing documents, statistics, literature, etc. is more appropriate. Instead, expert interviews are well suited to explore the expert's process knowledge coming from their insight into procedures, interactions, organisational constellations, issues, etc. Process knowledge is a form of experience which is often not documented comprehensively but exists implicitly only. In addition, the experts' interpretive knowledge as represented in her/his subjective perception or explanation patterns can be obtained (Bogner et al., 2014). The advantage of expert interviews is their pragmatism to quickly gain profound information, however a detailed preparation and follow-up is necessary (Figure 2). 


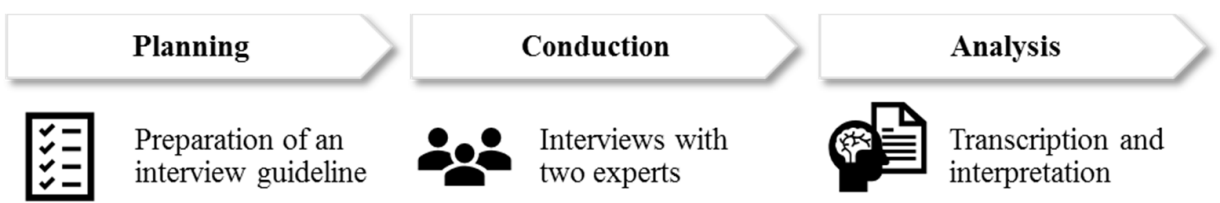

Figure 2. Procedure of the expert interviews in this case study

\section{Planning}

The expert interviews were chosen to be semi structured in line with (Bogner et al., 2014), so from the initial problem description derived questions were structured to serve as a guideline and check-list during the interviews. The first questions aim for investigating the actual process of defining the first set of requirements for new products, who is involved and how specific the requirements are. Further questions address the actual approaches and methods as well as the challenges and need for action from their point of view. These questions were then adapted for both interview partners regarding to their position within the company.

\section{Conduction}

Each interview took 1.5 hours. Expert 1 is responsible for product lifecycle management and methodical support at the case company. His division's tasks are i.a. the steady development and support of requirements engineering (RE) activities. Expert 2 is a project manager for development projects of drives, embedded software and technology. Their different insights allowed to compare a RE-process designing and an application-oriented perspective.

\section{Analysis}

To enable a comprehensive analysis the recorded interviews were first transcribed and then interpreted. A concept based on the qualitative content analysis according to Mayring (2010) and a category system according to Gläser and Laudel (2004) was chosen to handle the large amount of data: In iterative loops, categories (e.g. mentioned issues, design examples, approaches/methods, process phases) were formed to structure the transcribed content of both interviews, then compared, interpreted and summarised.

\subsection{Context: Corporate structure and development situation}

The Hilti corporation is an international power tool company that provides products and services for professional construction applications.

This case study focuses on the start of the development project for a new power tool, e.g. the new generation of an existing combi hammer. Such projects are organised by the product owning business unit, but the development of its drive is implemented in a separate department, which merges the development of drives for all power tools to achieve synergy effects. The drive mainly determines the performance, weight and differentiation of the products. This development unit is specifically characterised by interdisciplinary teamwork since drive modules are mechatronic systems consisting of a motor, a switch, motor electronics, human-machine-interface, embedded software and a battery or power cord (Figure 3, left side). Furthermore, their development activities must be synchronised (Figure 3 , right side) with the business units of the superordinate product and the other components, which is a big challenge in development projects of new power tools.
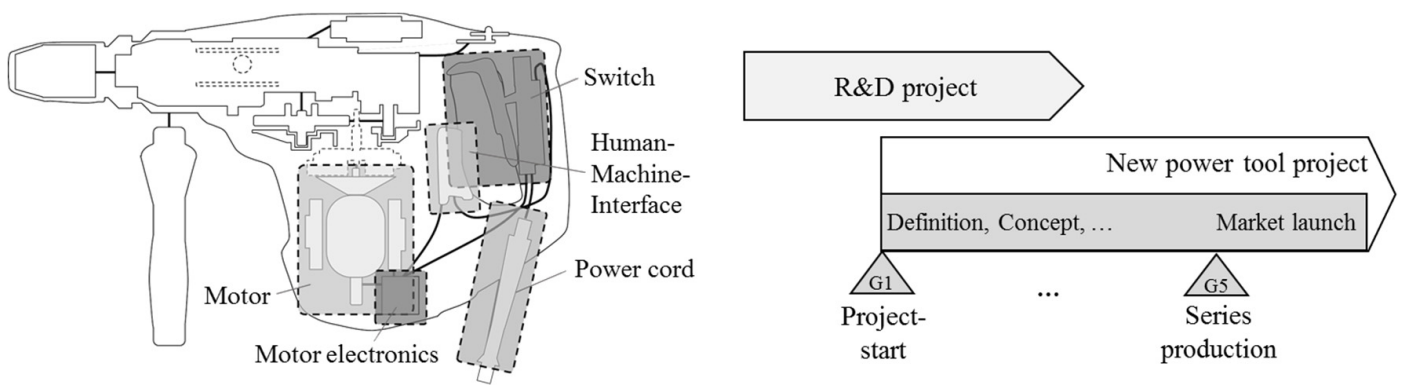

Figure 3. Drive components of an electric combi hammer (left side); sequence of R\&D projects and development projects of new power tools (right side) 
New products at Hilti are developed in a stage-gate-process (Windheim et al., 2016). When the project starts (G1), further relevant disciplines like production, marketing and supply have to be involved. To avoid time and money consuming loops resulting from immature technologies or a lack of system understanding, a product concept with technologies that reach a certain maturity has to be designed on beforehand (Ponn, 2015). Though the development starts based on an existing product, defining product requirements that are both ambitious and realistic is very complicated, as it will be explained below.

\subsection{Findings}

The development and requirements engineering processes at Hilti are very advanced which was not only a résumé of the interviews, but it is underlined by Hilti's success. Even so, the employees are still facing challenges due to the complexity of the introduced problem and there are important starting points for improvement by methodical support. Based on the problem description and on the analysis of the interviews, the following three hypotheses were derived and are substantiated with the findings.

H1: In the phase of product planning, key requirements are often still vague but when formally documented as a basis for cooperation they are formulated either too sharp or too fuzzy

Before the first gate of the development project, the objectives for the new product have to be set. Generally, new products shall contribute to Hilti's strategy of differentiating products, hence, improve the overall performance, compactness, or ergonomics of the product. Besides, the development projects underlie economic principles, e.g. minimizing the development expenses or lead time. Considering the available and possible solutions, these objectives are contradictory: A higher power output can be realised by a bigger motor which increases the weight. However, the development of a more efficient motor, e.g. with a higher performance-to-weight ratio, generally requires a higher development effort which results in increasing expenses. Nevertheless, the initially defined requirement set shall contribute to the products later innovativeness and thus are precisely defined, being aware that not every of these requirements can be met simultaneously and underlie uncertainties as they are defined at an early stage. On the other hand, especially technical requirements regarding single components remain fuzzy, because the impacts on the interfaces with other components and on the whole system cannot be fully assessed yet. To concretise a product concept, very precise data of single components are needed. Starting the design process with assumptions for one module (e.g. the human-machine-interface) knowing that iterations will be necessary - proved to be useful and based on the expertise and long experience a preferred order has established. Thereby an initial set of requirements can be defined to start the development. In order to reduce avoidable iterations, this initial set should be as reliable and accurate as possible.

A central challenge in defining the requirements of each component is to break down superordinate requirements like the key requirements. To answer questions such as 'Which component must or can contribute to which proportion of the required weight reduction?' a systemic view, that combines a detailed technical understanding of each component and coordinative skills, is required. However, this assessment is a complex task with rather high uncertainty. Hence, the development teams must approximate the solution in iterative steps. Each team tries to realise the same percentage of these requirements in the design of their respective component first. What can really be achieved by each component must be assessed in detail to evaluate possible arrangements and finally define specific and more robust requirements.

\section{H2: Defining requirements is a conflict "modest low-risk goals" vs. "ambitious high-risk goals"}

As described in $\mathrm{H} 1$, the initially defined requirements are very uncertain and become more dependable only with an increasing maturity of the developed product. The main difficulty is to decide how high the target value of a requirement must and can be set. Because Hilti's market strategy is to provide premium solutions, their products must reach the optimum in performance and reliability. Consequently, the requirements have to be very ambitious in the first place, but simultaneously as low-risk as possible. In the past, requirements were often set ambitious, with the risk of iterations and thus, longer lead times. Whether the project starts or not is decided in the first gate, where the potential project is presented to the review-members including management levels of the product-owning business units. If the maturity 
of the concept is insufficient and thus the risk of a project failure is assessed as too high, this gate will not be passed and the concept has to be redesigned.

Realising a very ambitious requirement is not the biggest challenge, but complex problems that cause immature product concepts arise in a set of conflictual ambitious requirements. Conflicts can be solved by finding compromises. But companies, which have a respective position in markets, such as Hilti, seek for the optimum, so it is very difficult to lower the own aspirations regarding each requirement. However, finding compromises is supported by defining "shall" (minimum) and "should" (wish) values for the key requirements. Moreover, the requirements must be prioritised to decide which requirement can be lowered. Within these given tolerances, it is the responsibility of the development teams to prioritise the requirements and identify a balanced solution.

\section{H3: Finding and evaluating compromises can be supported by the identification and comparison of tolerance ranges for a) achievable customer benefit and b) related development effort}

The valuable benefit of defining tolerance ranges between "shall" and "should" is that a clear limit is given. As long as the minimum requirements are not achieved, the design is adjusted until it meets the given boundaries. However, tolerance ranges are always set challenging. This is especially challenging when taking the modular product approach of the power tools into account, meaning that one product is not designed independently but within a complex product program. First, the marketing department defines requirements from a customers' point-of-view, though they do not have a feasible design concept yet. These initial requirements are elicited by either market pull (e.g. customer surveys, competitor's products) or technology push. After starting the product design and combining the required power outcome with the required assembly space, weight, feature contents and costs, the conflicting requirements become obvious lead to challenges in re-defining the requirement boundaries.

Defining "shall" and "should" is a hard confrontation. Concepts and potentials are presented and assessed. When it does not match the expectations, single requirements can be lowered. Then e.g. the motor can be smaller and this way they approach iteratively. But the approach is always initiated by the technological side, therefore it is essential to evaluate the impact of technical changes on product differentiation and perceived product value. For instance, by changing the windings of an electric motor, its output power can be increased to a certain amount, but for more power, the stack length has to be adjusted which causes higher efforts, compared to changing windings. Innovative technologies with higher potentials may also require new competences, tools and resources. Hence, knowing these limits does not only allow to define the requirements' tolerances, but in turn to show design potentials for anticipated requirement changes and the necessary development efforts. It has to be ensured that a positive business case exists for the defined requirement profiles. The correlation between perceived customer benefits behind each of the requirements is not always ensured. The challenge is to translate qualitative statements from customers into technical specifications and thus, product design. Topics like 'The product must be suitable for the work on a construction site' are translated by marketing into initial specific requirements as e.g. 'The product must withstand a fall from $2 \mathrm{~m}$ (shall) to $3 \mathrm{~m}$ (should) height'. As knowing exact tolerance ranges of technical solutions and the necessary development effort, also reliable tolerance ranges for the achievable customer benefit must be identified to prioritise requirements and enable the evaluation of possible compromises.

\section{Conclusion and outlook}

Despite both the development and requirements engineering processes at Hilti are very advanced, the way to approach operational development tasks can be characterised as informal and experience-based, so it differs depending on the experience and working style of the involved team members (see also Ponn, 2015). This case study initially exemplified that the requirements definition in the early fuzzyfront-end of product development is a complex process and associated with uncertainties (H1). In this context, a big challenge arises in coordinating the breakdown of product requirements and specifying them for single components (sub-systems), since the development is shared by different departments and each component incorporates different contribution potentials to meet the overall requirements. Especially when it comes to identifying compromises between conflicting requirements $(\mathrm{H} 2)$, a systematic methodical approach is needed. That would enable e.g. new employees to understand the 
implicit, intuitive considerations and procedure of experienced experts. This helps to reduce iterations and thereby to improve the average progress of such development projects.

In order to identify a mature (minimum-risk of failure) concept with optimal fulfilment of given requirements, it has turned out that analysing the tolerance ranges of the achievable customer benefit compared to the feasible/affordable development effort for overall key requirements at least is necessary (H3) (see also Song et al., 2017). Determining these two ranges for the key requirements of the whole product and of relevant components to show their potential of contribution, would allow to identify and compare potential design concepts. On that basis, the requirements can be prioritised transparently by the involved disciplines/departments. On this basis suitable compromises between contradicting requirements and the best set of achievable requirements can be identified. The aim for next steps is therefore to support interdisciplinary work by providing a guideline and a transparent basis for design discussions. As the interviews made also clear, this would be much more practical than having a method to calculate an exact optimum value for each requirement. Considering the boundary conditions and influencing factors for every development case (if possible at all) would be too complex in application. Even in advanced large companies with many method-affine employees, the introduction and application of new (even simple) methods already encounters high barriers anyway.

By developing a suitable support for requirements definition and prioritisation based on these hypotheses, the previous mentioned context of drive module development is included in further studies. Subsequent research will aim at verifying the hypotheses as stated in this initial case study in other companies and industries. Furthermore, we aim at supporting the requirements definition and prioritization in product development projects.

\section{References}

Aguirre-Ollinger, G. and Stahovich, T.F. (2004), "RedesignIT - A Model-Based Tool for Managing Design Changes", Journal of Mechanical Design, Vol. 126 No. 2, pp. 208-216. https://doi.org/10.1115/1.1666888

Akao, Y. (2004), Quality Function Deployment (QFD): Integrating Customer Requirements into Product Design, Taylor \& Francis, Productivity Press, Portland.

Albers, A., Bursac, N. and Wintergerst, E. (2015), "Product generation development - importance and challenges from a design research perspective", In: Mastorakis, N.E. and To, C.W.S. (Eds.), New Developments in Mechanics and Mechanical Engineering, pp. 16-21.

Bamberg, G. and Baur, F. (1998), Statistik. Oldenbourger Lehr-und Handbücher der Wirtschafts- und Sozialwissenschaften, 10th ed., Oldenburg.

Blessing, L. and Chakrabarti, A. (2009), DRM. A Design Research Methodology, Springer-Verlag, London. https://doi.org/10.1007/978-1-84882-587-1

Bogner, A., Littig, B. and Menz, W. (2014), Interviews mit Experten. Eine praxisorientierte Einführung, SpringerVerlag, Wiesbaden. https://doi.org/10.1007/978-3-531-19416-5

Borchardt, A. and Göthlich, S.E. (2007), "Erkenntnisgewinn durch Fallstudien", In: Albers, S., Klapper, D. Konradt, U., Walter, A. and Wolf, J. (Eds.), Methodik der empirischen Forschung, Gabler Verlag, Wiesbaden. https://doi.org/10.1007/978-3-8349-9121-8_3

Browning, T.R. and Eppinger, S.D. (2002), "Modeling impacts of process architecture on cost and schedule risk in product development", IEEE Transactions on Engineering Management, Vol. 49 No. 4, pp. 428-442. https://doi.org/10.1109/TEM.2002.806709

Chua, D.K.H. and Hossain, M.A. (2012), "Predicting change propagation and impact on design schedule due to external changes", IEEE Transactions on Engineering Management, Vol. 59 No. 3, pp. 483-493. https://doi.org/10.1109/TEM.2011.2164082

Clarkson, P.J., Simons, C. and Eckert, C. (2004), "Predicting change propagation in complex design", Journal of Mechanical Design, Vol. 126 No. 5, pp. 788-797. https://doi.org/10.1115/1.1765117

Cooper, R.G. (2002), Top oder Flop in der Produktentwicklung. Erfolgsstrategien: Von der Idee zum Launch, Wiley-VCH Verlag, Weinheim.

Eckert, C.M., Alink, T. and Albers, A. (2010), "Issue driven analysis of an existing product at different levels of abstraction", Proceedings of DESIGN 2010 / the $11^{\text {th }}$ International DESIGN Conference, Dubrovnik, Croatia, May 17-20, 2010, pp. 673-682.

Ehrlenspiel, K. (2009), Integrierte Produktentwicklung: Denkabläufe, Methodeneinsatz, Zusammenarbeit, 4th ed., Carl Hanser Verlag, München, Wien. https://doi.org/10.3139/9783446421578

Eisenhardt, K.M. (1989), "Building theories from case study research", Academy of management review, Vol. 14 No. 4, pp. 532-550. https://doi.org/10.2307/258557 
Ericson, A. and Kastensson, A. (2011), "Exploit and Explore: Two Ways of Categorizing Innovation Projects", Proceedings of ICED'11 / the $18^{\text {th }}$ International Conference on Engineering Design, Vol. 3, Copenhagen, Denmark, August 15-18, 2011, pp. 284-293.

Feldhusen, J. and Grote, K.-H. (2013), Pahl/Beitz Konstruktionslehre. Methoden und Anwendung erfolgreicher Produktentwicklung, Springer, Berlin, Heidelberg. https://doi.org/10.1007/978-3-642-29569-0

Gericke, K., Meißner, M. and Paetzold, K. (2013), "Understanding the context of product development", Proceedings of ICED'13 / the 19th International Conference on Engineering Design, Vol. 3, Seoul, Korea, August 19-22, 2013, The Design Society, Glasgow, pp. 191-200.

Gläser, J. and Laudel, G. (2004), Experteninterviews und qualitative Inhaltsanalyse, VS Verlag für Sozialwissenschaften, Wiesbaden.

Incose (2011), SE Handbook Working Group: Systems Engineering Handbook - A Guide for System Life Cycle Processes and Activities, INCOSE, San Diego, California.

Jarratt, T., Eckert, C., Caldwell, N.H.M. and Clarkson, P.J. (2011), "Engineering Change: an overview and perspective on the literature", Research Engineering Design, Vol. 22 No. 2, pp. 103-124. https://doi.org/10.1007/s00163-010-0097-y

Kano, N., Seraku, N., Takahashi, F. and Tsuji S.-i. (1984), “Attractive Quality and Must-be Quality”, Journal of the Japanese Society for Quality Control, Vol. 14 No. 2, pp. 147-156.

Koh, E.C.Y., Caldwell, N.H.M. and Clarkson, P.J. (2012), "A method to assess the effects of engineering change propagation”, Research in Engineering Design, Vol. 23 No. 4, pp. 329-351. https://doi.org/10.1007/s00163012-0131-3

Mayring, P. (2010), Qualitative Inhaltsanalyse: Grundlagen und Techniken, 11th ed., Beltz Verlag, Weinheim.

McManus, H. and Hastings, D. (2006), "A Framework for Understanding Uncertainty and its Mitigation and Exploitation in Complex Systems", IEEE Engineering Management Review, Vol. 34 No. 3, p. 81. https://doi.org/10.1109/EMR.2006.261384

Muschik, S. (2011), Development of Systems of Objectives in Early Product Engineering - Entwicklung von Zielsystemen in der frühen Produktentstehung, PhD thesis, Karlsruher Institut für Technologie.

Oerding, J. (2009), Ein Beitrag zum Modellverständnis der Produktentstehung - Strukturierung von Zielsystemen mittels C\&CM, PhD thesis, Karlsruher Institut für Technologie.

Pahl, G., Beitz, W., Feldhusen, J. and Grote, K.-H. (2007), Engineering design: A systematic approach, 3rd ed., Springer, London. https://doi.org/10.1007/978-1-84628-319-2

Pohl, K. (2010), Requirements Engineering: Fundamentals, Principles, and Techniques, Springer, Berlin.

Ponn, J. (2015), "Portfolio management for electric drives in powertools at Hilti: Challenges and solution approaches", Proceedings of ICED'15 / the 20th International Conference on Engineering Design, Vol. 7, Milan, Italy, July 27-30, 2015, The Design Society, Glasgow, pp. 105-114.

Roser, C., Kazmer, D. and Rinderle, J. (2003), “An Economic Design Change Method”, Journal of Mechanical Design, Vol. 125 No. 2, pp. 233-239. https://doi.org/10.1115/1.1561040

Song, Y., Chahin, A., Scholle, P., Bender, B., Gräßler, I. and Paetzold, K. (2017), "Optimierung des Produktentwicklungsprozesses mittels Risikoanalyse vernetzter Anforderungen”, Proceedings of DfX 2017 / the 28th Symposium Design for X, Bamberg, Germany, October 4-5, 2017, Tutech Verlag, Hamburg, pp. 339351

Stockstrom, C. and Herstatt, C. (2008), "Planning and uncertainty in new product development", $R \& D$ Management, Vol. 38 No. 5, pp. 480-490. https://doi.org/10.1111/j.1467-9310.2008.00532.x

Vajna, S. (2014), Integrated Design Engineering. Ein interdisziplinäres Modell für die ganzheitliche Produktentwicklung, Springer Vieweg, Berlin, Heidelberg. https://doi.org/10.1007/978-3-642-41104-5

Windheim, M., Hack1, J., Gebhardt, N. and Krause, D. (2016), "Assessing impacts of modular product architectures on the firm: a case study", Proceedings of the DESIGN 2016 / the $14^{\text {th }}$ International Design Conference, Dubrovnik, Croatia, May 16-19, 2016, The Design Society, Glasgow, pp. 1445-1454.

Wyatt, D.F., Eckert, C.M. and Clarkson, P.J. (2009), "Design of product architectures in incrementally developed complex products", Proceedings of ICED'09 / the 17 th International Conference on Engineering Design, Vol. 4, Stanford, USA, August 24-27, 2009, The Design Society, Glasgow, pp. 167-178.

Yin, R.K. (2014), Case Study Research: Design and Methods, 5th ed., Sage, Los Angeles, California.

Zehnter, C., Burger, A. and Ovtcharova, J. (2012), Key-Performance-Analyse von Methoden des Anforderungsmanagements, KIT Scientific Reports 7620, KIT Scientific Publishing, Karlsruhe.

Young-Woo Song, M. Sc.

Ruhr-Universität Bochum, Chair of Product Development

Universitätsstraße 150, 44801 Bochum, Germany

Email: song@1pe.rub.de 